\title{
Havens en georganiseerde criminaliteit: een historische bespiegeling
}

\section{Cyrille Fijnaut*}

In de loop van de jaren tachtig kreeg ik belangstelling voor de rol die havens spelen in het bedrijven van bepaalde vormen van georganiseerde misdaad. Enerzijds de vorm waarbij illegale goederen, personen en geld over grenzen, en dus ook door havens, worden gesmokkeld. Anderzijds de vorm waarbij de legale activiteiten in havens het mikpunt vormen van stelselmatige afpersing en diefstal. Deze belangstelling werd in het bijzonder aangewakkerd door de publicaties van Pino Arlacchi over de Italiaanse maffia en door onderzoeken van de New York State Organized Crime Task Force naar de rol van de Cosa Nostra in de economie van de Big Apple. In deze bijdrage zal eerst worden aangestipt wat deze bronnen mij leerden over de genoemde verschijningsvormen van georganiseerde misdaad en hoe ik in 1990 - op uitnodiging van de toenmalige burgemeester van Rotterdam, B. Peper - de Rotterdamse havenbaronnen bijpraatte over de mogelijke risico's van georganiseerde misdaad voor een goede, en dus ook integere, werking van de haven. Daarna wordt ingegaan op het wetenschappelijke en beleidsmatige onderzoek dat sinds de commissie-Van Traa in 1995-1996 is verricht naar de rol die de Rotterdamse haven - op zichzelf en in vergelijking met de haven van Antwerpen - speelt in de nationale en internationale georganiseerde misdaad. Tot slot wordt stilgestaan bij de moeizame omgang met het cruciale maar netelige probleem dat al in het overleg met burgemeester Peper en de havenbaronnen in 1990 een centrale rol speelde: de integriteit van de werking van de Rotterdamse haven.

* Em. prof. dr. C.J. Fijnaut is emeritus hoogleraar criminologie aan de Universiteit Tilburg. Dit artikel is een bewerking van een voordracht gehouden op het symposium over de aanpak van drugscriminaliteit in de Rotterdamse haven aan de Erasmus Universiteit Rotterdam op 12 september 2019 . 


\section{Twee bronnen van inspiratie}

In zijn boek Mafia business beschrijft Arlacchi hoe diverse $\operatorname{cosche}^{1}$ van de Calabrese maffia, de 'ndrangheta, nauw betrokken waren bij de uitbouw van de haven van Gioia Tauro (Arlacchi 1986, p. 88-116). Uitgerekend de baas van de Piromalli-cosca werd in 1994 zelfs de partij waarmee een hele grote Italiaanse bouwonderneming een overeenkomst sloot om met steun van de nationale regering en geld van de Europese Commissie deze haven te transformeren tot een omslagpunt voor grootschalig containervervoer in de Middellandse Zee (1,5 miljoen containers per jaar) en de bijbehorende infrastructuur geschikt te maken voor industrialisering van de streek (Paoli 2003, p. 152-168). Met alle gevolgen van dien: niet alleen werden langs duistere wegen veel opdrachten toebedeeld aan maffiose (onder)aannemers, er kwam ook niet veel terecht van de bouwplannen, de bouw van een grote vuilverbrandingsoven uitgezonderd, zoals uit een Arteuitzending over de Italiaanse maffia op 27 augustus 2019 bleek. Wie tegen de gang van zaken protesteerde, kreeg te maken met intimidatie of erger.

Al vlug bleek dat de haven, die in 1999 feestelijk werd geopend, om reden van slecht management, concurrentie van andere havens, overheidsbureaucratie en gebrek aan bekwame ondernemers niet winstgevend was. Maar er is meer. Uit een rapport van de parlementaire AntiMaffia Commissie uit 2008, een evaluatie van het project uit 2012 door een particulier bedrijf voor de Commissie, en een recente studie van een Amerikaanse student blijkt dat de 'ndrangheta altijd grote invloed is blijven uitoefenen op de organisatie en werking van de haven (CSIL 2012; Commissione parlamentare 2008; White 2018). Havenbedrijven worden, desnoods met intimidatie en geweld, verplicht om in zee te gaan met maffiose ondernemingen. Handlangers van de 'ndrangheta zijn betrokken bij de uitoefening van de douanecontrole. De meest invloedrijke cosche krijgen \$1,5 voor elke container die wordt gelost of geladen. Het is dus niet verbazingwekkend dat de beoogde economische opbloei van de streek uitblijft. Ondernemers hebben geen zin om onder de knoet van de 'ndrangheta te werken.

Verder staat vast dat de haven volop wordt gebruikt voor de invoer van illegale wapens en cocaïne. Der Spiegel berichtte zeer onlangs nog - op

1 Cosche zijn min of meer zelfstandige, op familiebanden gebaseerde groepen binnen de maffia (van cosca, blad van een artisjok). 
14 november 2019 - dat er 1200 kilo cocaïne was gevonden in containers met bananen. Ook worden via deze haven massa's toxisch afval uit Noord-Italië en West-Europa ingevoerd in Calabrië. De maffiosi verwerken dit afval niet, maar storten het gewoon in de bergen, in de rivieren en in het open veld. $\mathrm{Zij}$ vergiftigen zo niet alleen hun eigen territorium, inclusief fauna en flora, maar ook de mensen die er leven. De New York State Organized Crime Task Force maakte in de jaren tachtig zichtbaar hoe met name de Genovese family fortuin maakte met de stelselmatige afpersing van de bedrijven die opereerden op de toen grootste vismijn aan de westkust van de Verenigde Staten: de Fulton Fish Market in New York. Zo werden de unloaders, die de aangevoerde vis in kleinere kisten verpakten, gedwongen een deel van hun inkomsten af te geven. De bedrijven die niet wilden betalen, werden bedreigd met geweld, diefstal en werkonderbrekingen. Ook de vissers zelf stonden onder controle van deze family. Als er werd gevreesd voor overaanbod en dus voor prijsverlaging, moesten zij hun vangst in zee dumpen (Carroll 1991; Jacobs e.a. 1999, p. 33-47).

Soortgelijke praktijken stonden in de jaren tachtig overigens ook in berichten over de greep van de Japanse yakuza op onder meer de haven van Kobe. Die hief een soort van belasting op alle goederen die in deze haven werden overgeslagen. En iedereen betaalde die belasting, want de sanctie was duidelijk: goederen werden niet geladen of gelost.

\section{Burgemeester Peper en de Rotterdamse havenbaronnen}

Gewapend met de inzichten van Arlacchi en de genoemde Task Force nam ik - blijkens mijn agenda van toen - begin 1990 de uitnodiging van burgemeester B. Peper aan om met hem en een aantal belangrijke spelers in de Rotterdamse haven te overleggen over de risico's van georganiseerde misdaad voor deze haven. Ik weet niet meer hoe hij bij mij uitkwam. Wellicht naar aanleiding van mijn bijdragen in diverse publicaties over deze vorm van misdaad (Fijnaut 1985; 1989). Hoe dan ook, op 17 mei 1990 zat ik op het stadhuis met zo'n 25 havenbaronnen. Voor zover ik mij kan herinneren, kwam mijn betoog in dit gezelschap neer op het volgende:

- Havens - zeehavens evengoed als luchthavens - zijn zeer belangrijk in de sfeer van de georganiseerde misdaad: deze misdaad 
bestaat in onze contreien immers voor het overgrote deel uit smokkel - goederen, mensen en kapitaal/geld - vanuit en naar derde landen.

- De rol die georganiseerde misdaad in havens in dezen kan spelen, vormt een soort van spectrum: zij gaat van de in- en uitvoer van illegale mensen, goederen en kapitaal, door ze te laten meeliften op de stromen van legale mensen, goederen en kapitaal, controle over respectievelijk uitbuiting van de legale bedrijvigheden: via eigendom van bedrijven, een monopolie op de overslag of controle op havenpersoneel.

- Het ligt voor de hand dat het een in het verlengde van het ander kan liggen: hoe sterker de criminele controle op de werking van een haven is, des te makkelijker is het om de invoer en uitvoer van illegale mensen, goederen en kapitaal te organiseren; het is dus belangrijk om de dynamiek van de georganiseerde misdaad in havens scherp in het oog te houden.

- Corruptie, zowel in de publieke sfeer (douane en politie) als in de private sfeer (overslagbedrijven e.d.), kan een belangrijke rol spelen bij de smokkelpraktijken; zij kan worden tegengegaan met maatregelen om de integriteit te vergroten, zoals screening en wisseling van personeel en strakke procedures bij de afhandeling van transacties.

- Het commerciële belang van een integere haven is zeer groot in het licht van de plannen om te komen tot een interne/geïntegreerde markt in de Europese Gemeenschap/Europese Unie, onder meer door de afschaffing van de controles aan de binnengrenzen en hun verlegging naar de buitengrenzen: als integere vervoerders/verladers het voor het kiezen hebben, dan zullen zij zeker kiezen voor een integere en dus ook veilige haven.

In het licht van het vorenstaande valt goed te begrijpen dat in de rapporten die de onderzoeksgroep-Fijnaut in 1986 schreef voor de commissie-Van Traa nogal wat aandacht wordt geschonken aan de rol van de Rotterdamse haven bij het bedrijven van georganiseerde misdaad.

\section{Het rapport van het Wadden-team}

De eerste bevinding van de onderzoeksgroep was eigenlijk een vondst: een dubbeldik rapport van het zogenoemde Wadden-team uit 1988 
over met name de invoer van hasj uit Pakistan. ${ }^{2}$ In dit rapport wordt beschreven dat het voor smokkelaars uit omgeving Amsterdam en West-Brabant heel gemakkelijk was om schepen en schippers te vinden die grote partijen in Pakistan wilden ophalen. Soms werden de partijen afgezet in Galicië en vandaar over de weg vervoerd naar Nederland. Meer gebruikelijk was echter dat de hasj per schip werd ingevoerd via Nederlandse havens, dan wel vanaf een schip met speedboten op de kust werd aangeland. De hasj werd dan van hieruit doorgevoerd naar andere Europese landen. Men had slechts een beperkt idee van de mensen die dit allemaal organiseerden en financierden. Duidelijk was wel dat zij beschikten over juridische raadgevers om nepbedrijven op te richten.

Deze bevinding is nog altijd relevant voor de huidige discussie over maatregelen om de invoer van cocaïne te stoppen of te beperken. Zij demonstreert dat men zich niet moet blindstaren op de rol die de Rotterdamse haven in deze handel speelt, maar ook niet op de rol van andere grote Nederlandse en buitenlandse zeehavens. Wanneer in deze havens de controle wordt opgevoerd, moet worden verwacht dat de smokkelaars overgaan tot invoer via kleinere havens in Nederland en de omringende landen. En wanneer ook hier strengere controlemaatregelen worden getroffen - denk aan de toenemende controle in de vele (jacht)havens rondom de Westerschelde -, dan blijft de aanlanding van deze drug op de kust nog altijd een gerede optie. Dit vindt tegenwoordig al af en toe plaats, maar zou dan op (veel) grote(re) schaal kunnen gebeuren (Berkelder \& De Ree 2005).

Dat zich dergelijke vormen van verplaatsing kunnen en zullen voordoen, kan overigens ook worden afgeleid uit ervaringen in het buitenland. In mijn knipselkrant zitten heel wat actuele voorbeelden van aanlandingen op de kust van Spanje en Portugal, Marokko, Australië en Nieuw-Zeeland. Verscherping van de controle in de Rotterdamse haven, waar ook vandaag de dag weer voor wordt gepleit, betekent dus zeker niet het einde van de grootschalige invoer van cocaïne in Nederland. 


\section{Het eigen onderzoek voor de commissie-Van Traa}

De onderzoeksgroep-Fijnaut stelde vast dat de Rotterdamse haven in de jaren tachtig en negentig kampte met (container)diefstallen die werden gepleegd door professionele dievenbendes. ${ }^{3}$ Deze criminele groepen beschikten in de haven over een groot netwerk van informanten en helpers, bestaande uit portiers, loodsbazen en chauffeurs. In zekere zin was het dus niets nieuws dat op een gegeven moment 'uithalers' partijen drugs uit containerschepen haalden. Hun professionaliteit belette niet dat er ook toen al vrij grote hoeveelheden drugs in beslag werden genomen. Zo werd er in 1993118.000 kilo drugs (hasj, marihuana en coke) gepakt (waarvan 2605 kilo cocaïne). In 1994 ging het om 188.000 kilo, waarvan 6171 kilo cocaïne. Niettemin wist iedereen ook dat - gelet op de grote aantallen containers en het hoge tempo van afhandeling - deze hoeveelheden weinig zeiden over de totale hoeveelheden illegale drugs die werden ingevoerd. De feitelijke pakkans was nu eenmaal gering. Het transitverkeer kon niet vaak en niet lang worden stilgelegd voor de uitvoering van daadwerkelijke controles: in de haven is snelheid nu eenmaal alles. De oprichting van een Douane Informatie Centrum kon wel leiden tot vergroting van de pakkans, maar betekende zeker niet het einde van de illegale drugshandel. In het betrokken rapport van de onderzoeksgroep-Fijnaut wordt hierbij speciaal gewezen op het feit dat de Colombiaanse smokkelaars vaak probeerden om de geografische herkomst van het schip of de containers te maskeren. De middelen die zij gebruikten om het illegale transport zélf te verhullen, waren onder meer valse of vervalste ladingbrieven, containers met dubbele wanden en blikken met fruit of fruitsappen. Zij vonden het overigens niet zo erg om partijen cocaïne kwijt te raken aan de politie of de douane. De winsten waren zo enorm dat zij dergelijke verliezen voor lief namen. Zij probeerden wel om via malafide en bonafide scheepvaartbedrijven eigen logistieke voorzieningen in de haven op te bouwen en zo hun slaagkansen te vergroten, maar om de een of andere reden kregen zij dit niet voor elkaar. Hierdoor bleven zij op allerlei terreinen aangewezen op medewerking vanuit de Rotterdamse onderwereld.

Het proefschrift van Zaitch uit 2001 over de cocaïnehandel via de haven van Rotterdam maakte duidelijk waarom Nederland zo aanlok-

3 Zie voor dit onderzoek inzake de Rotterdamse haven onder meer: Kamerstukken II 1995/96, 24072, nr. 17, p. 40-41, 50-51, 172-179. 
kelijk was voor Colombiaanse cocaïnesmokkelaars: een bedrijvig land met een goede infrastructuur, prima verbindingen naar andere landen en geen zware straffen. Bovendien waren de controlesystemen in de haven geen probleem voor hen. Integendeel, zij smokkelden juist graag via Rotterdam omdat de afhandeling van de containers er zo snel verliep en de controle op hun inhoud zo beperkt was. Volgens de zegslieden van Zaitch was het in Rotterdam dan ook helemaal niet nodig om iemand te corrumperen: 'You don't need corruption with so many legal business around' (Zaitch 2002). Zij verkneukelden zich trouwens bij de gedachte dat de havenautoriteiten het tempo nog wilden opvoeren: 'And now they want to make it even faster' (Zaitch 2002, p. 243). En dan te bedenken dat vandaag de dag de douane er op haar website prat op gaat dat zij 24/7 in bedrijf is en bekendstaat als 'een van de efficiëntste douanes ter wereld'.

Overigens werd door de onderzoeksgroep-Fijnaut niet vastgesteld dat Nederlandse of buitenlandse criminele groepen zodanig waren genesteld in de Rotterdamse haven dat zij er op de een of andere manier legale trafieken konden controleren. Er was dus geen sprake van stelselmatige afpersing van bedrijven of van stelselmatige corruptie en (dreiging met) geweld ten aanzien van medewerkers van de douane en de Politie Rotterdam-Rijnmond. Wat niet wil zeggen dat er geen verhalen waren over corrupte douaniers of politiemensen. Slechts in een enkel geval werd corruptie echter daadwerkelijk vastgesteld. Via de oprichting van een Platform Criminaliteitsbeheersing Rotterdam tussen publieke en private partijen werd trouwens geprobeerd om de integriteit van de bedrijfsvoering in de haven te bewaken.

\section{De ontwikkelingen in de periode 2002-2017}

Dit beeld van de situatie in de Rotterdamse haven werd een jaar later bevestigd in de tweede rapportage over de georganiseerde misdaad in Nederland op basis van de desbetreffende WODC-monitor (Kleemans e.a. 2002, p. 92 e.v.). In de vijftien strafzaken met betrekking tot de invoer van cocaïne (in tien gevallen per schip via de zeehavens) was niet of nauwelijks sprake van aanwijzingen voor (de noodzaak van) corruptie. De modi operandi van de smokkelaars waren daarentegen bovenal gericht op het omzeilen van toezicht. Het ging er dus niet om douaniers een oogje te laten dichtknijpen, maar om de smokkel zo 
veel als mogelijk te onttrekken aan hun wakend oog. En dit temeer omdat het volgens de smokkelaars moeilijk was om Nederlandse douaniers om te kopen. Het was zelfs beter om het niet eens te proberen, want het risico was groot dat pogingen daartoe zich tegen je keerden. Wat niet wilde zeggen dat er geen sprake was van corruptie. Het was immers de vraag in hoeverre (geruchten over) corruptiepraktijken waren meegenomen in de strafrechtelijke onderzoeken die werden geanalyseerd. Het betreft hier immers dirty data, om met Marx (1984) te spreken. Men mag er dus niet blind op vertrouwen dat strafdossiers op dit punt een getrouw beeld van de situatie geven.

Uit een rapport over de cocaïnehandel voor de nationale criminaliteitsbeeldanalyse 2007 (Politie 2008) bleek dat de voornaamste methoden om cocaïnetransporten over zee te camoufleren nog altijd dezelfde waren als in de tijd van de commissie-Van Traa: valse of vervalste laadbrieven en plotse dan wel veelvuldige wijzigingen van de bestemming. Hier wordt deze keer wel als een soort van vanzelfsprekendheid aan toegevoegd (p. 91) dat in de havens van bestemming, en dus ook in Rotterdam, de cocaïne door 'omgekocht havenpersoneel' uit containers wordt verwijderd voordat die worden doorgestuurd naar de betrokken (legale) bedrijven. Deze bevinding zaaide natuurlijk niet alleen twijfel over de zojuist besproken uitkomsten van de WODC-monitor georganiseerde criminaliteit uit 2002, maar riep ook de vraag op of de corruptieproblemen ondertussen wellicht waren toegenomen. Deze vraag werd in deze analyse echter niet beantwoord. Ook in het Nationaal dreigingsbeeld 2017 (Boerman e.a. 2017, p. 35-44) gebeurt dit niet. Hierin wordt wel herhaald dat cocaïne, die bestemd is voor Nederlandse criminelen, niet alleen wordt geïmporteerd via de haven van Rotterdam, maar ook via de havens van Antwerpen, Amsterdam en Vlissingen. Om de smokkel te camoufleren wordt nog altijd gebruik gemaakt van (nep)bedrijven en katvangers. De drug zelf wordt bijvoorbeeld verborgen tussen de lading, in speciale bergplaatsen onder de waterlijn en in dubbele wanden in containers. Zonder verwijzing naar belangrijke artikelen die in de afgelopen jaren over de smokkel in Rotterdam en Schiphol zijn gepubliceerd (Eski \& Buijt 2016; Madarie \& Kruisbergen 2018) wordt hieraan toegevoegd dat werknemers bij containerbedrijven, vrachtwagenchauffeurs en douaniers onmisbare schakels vormen in de smokkel: om in containers te kunnen komen dan wel om ze te verplaatsen of te laten doorgaan. In het laatste geval worden er natuurlijk geen 'uithalers' - vaak Marokka- 
nen of Albanezen - meer ingezet om cocaïne van de schepen te halen, maar wordt op grote schaal de criminele variant van de gecontroleerde aflevering toegepast. Die houdt in dat de betrokken containers, al dan niet met medeweten van de verladers of de bestemde bedrijven, ver in het achterland worden bezorgd en pas daar - desnoods gewapenderhand - worden geopend door de smokkelaars of hun handlangers. Overigens wordt hier ook gewezen op het feit dat er nog steeds droppings in open water plaatsvinden en dat de drugs met snelle boten naar de kust worden gevaren.

Dit laatste onderstreept weer eens dat het niet zo zinvol is om bij de analyse van grensoverschrijdende drugssmokkel alleen naar de havens zélf te kijken. Om echt zicht op die smokkel te krijgen moeten op z'n minst ook de bedrijvigheden op bijbehorende haventerreinen of verder weg gelegen industrieterreinen worden bekeken, en zo mogelijk ook de rechtstreekse aanlanding van drugs op de kust. Havens mogen we dus niet als geïsoleerde transitiepunten zien, maar moeten worden beschouwd als knooppunten in netwerken die tot ver in het binnenland en het buitenland reiken. Alleen wie zo naar havens kijkt, ziet de ruimere strategische en tactische mogelijkheden om drugshandel te stoppen dan wel te verminderen. Neem het voorbeeld van de cocaïnetransporten: men zal moeten proberen te voorkomen dat zij kunnen starten in Zuid-Amerika, maar ook onder ogen moeten zien dat zij niet altijd in de Nederlandse (of Belgische dan wel Duitse) havens worden uitgehaald, maar op veilige plekken in het achterland.

\section{De resultaten van een Belgisch-Nederlands onderzoek}

Er wordt vandaag de dag van alles verteld over de drugssmokkel via de haven van Rotterdam. Veel van die verhalen hebben een zwakke empirische grondslag. Neem bijvoorbeeld het verhaal over de preponderante rol die de Rotterdamse haven in vergelijking met andere Europese havens zou spelen in de smokkel van cocaïne naar Europa. Er is echter geen deugdelijke vergelijkende studie waarin dit onomstotelijk is vastgesteld. Bovendien wordt in dit verband veelal uit het oog verloren dat soms meerdere havens - ook als afleidings- of afschermingsmaatregel - zijn betrokken bij een en dezelfde smokkeloperatie. Denk bijvoorbeeld aan het recente geval waarin 1,3 ton heroïne via Felixstowe moest worden vervoerd naar Antwerpen, maar door de Britse 
National Crime Agency werd onderschept en in Nederland leidde tot de arrestatie van vier verdachten. ${ }^{4}$

Het enige onderzoek waarin enigermate vergelijkenderwijze is gekeken naar de rol van Rotterdam in de drugssmokkel is het onderzoek naar de onderlinge verhouding tussen de drugsmarkten in België en Nederland dat in 2014 werd opgezet door de helaas te jong overleden Gentse hoogleraar Brice de Ruyver (Colman e.a. 2018, p. 187-207). Dit onderzoek laat zien dat er, mede gelet op het feit dat in Nederland de cannabisteelt en de productie van synthetische drugs niet afnemen, sprake is van expansie van de (Nederlandse) illegale drugsindustrie op Belgisch grondgebied. Met de kanttekening dat er in samenhang met deze expansie in toenemende mate sprake is van integratie van de Nederlandse en Belgische criminele milieus.

Waar het gaat om de rol van de havens in de drugssmokkel gaat de meeste aandacht in dit onderzoek naar de rol van de Antwerpse haven. Hiervan wordt onder andere gezegd dat met name Marokkaanse en Albanese groepen - zowel woonachtig/verblijvend in Antwerpen als in Belgisch Limburg en Luik - volop zijn betrokken bij het smokkelen/uithalen van cocaïne, en dat zij hierbij op de achtergrond worden geholpen door hun banden met 'ndrangheta-figuren die op Belgisch grondgebied opereren. Mede om deze reden maken ook Nederlandse criminele groepen - al dan niet familiaal verweven met criminele groepen in Antwerpen (dit speelt met name een rol in de Marokkaanse gemeenschap) - graag gebruik van de Antwerpse haven. Hier kunnen zij rekenen op verregaande criminele dienstverlening, ook waar het gaat om de ondersteuning door corrupte havenarbeiders, politiemensen en douaniers. Er wordt geschat dat tot $80 \%$ van de cocaïnetransporten via de haven van Antwerpen is bestemd voor Nederland. Deze situatie heeft overigens geleid tot een steeds gewelddadiger concurrentiestrijd tussen Antwerpse Marokkaanse groepen en Nederlandse criminele organisaties.

In het verlengde van deze vaststellingen worden ook andere factoren besproken die in de hand zouden werken dat de Antwerpse haven voor de smokkel van cocaïne veel belangrijker is dan de Rotterdamse haven: de uitgestrektheid van het Antwerpse havengebied, de hoge productiviteit van de Antwerpse haven bij de verwerking van containers en het geringere niveau van controle op de goederenstromen in

4 www.nieuwsbladtransport.nl/havens/2019/09/05/megavangst-heroine-in-felixstowe-leidttot-arrestaties-in-nederland/?gdpr=accept 
deze haven. Welke rol deze factoren werkelijk spelen in de verhouding tussen de Antwerpse haven en de Rotterdamse haven bij de import van cocaïne is naar mijn mening echter een vraag die nader onderzoek verdient. Deze vraag kan op grond van het onderzoek dat werd verricht in elk geval niet worden beantwoord, omdat er geen gedetailleerde kwantitatieve en kwalitatieve vergelijking tussen het grondgebied, de organisatie en de werking van deze twee havens werd gemaakt, juist ook waar het gaat om de aard, de omvang en de toepassing van allerhande controlemaatregelen. Bij gebrek aan een dergelijke vergelijkende analyse is het ook onmogelijk min of meer te kunnen bepalen wat de verschillen in hoeveelheden in beslag genomen drugs/ cocaïne tussen de beide havens betekenen. Zeggen die verschillen vooral iets over niveauverschillen tussen de controlesystemen die in de beide havens worden toegepast? En niets over de verschillen tussen de feitelijke hoeveelheden drugs die in de beide havens daadwerkelijk worden doorgevoerd?

Naast de eerdere vaststelling dat geregeld meerdere havens zijn betrokken bij een en dezelfde smokkeloperatie, is ook dit dark number-probleem een goede reden om te pleiten voor meer onderzoek door multinationale wetenschappelijke onderzoeksgroepen naar de rol van Europese havens - evengoed zeehavens als luchthavens - in de illegale drugshandel. Het onderzoek op dit gebied is veel te nationaal van opzet.

\section{Als de prooi de jager pakt}

Gegeven het grote belang van de kwestie van de integriteit van de Rotterdamse haven moeten tot slot nog enkele opmerkingen worden gemaakt over het onderzoek van B. Rovers en H. Moors, waarvan de resultaten niet worden gepubliceerd. Het doel van dit onderzoek - met de wat raadselachtige titel: Als de prooi de jager pakt - was om vanaf medio 2016 gefundeerd zicht te krijgen op de kwetsbaarheid van THOR-organisaties (Toezicht, Handhaving, Opsporing en Regelgeving/vergunningverlening) in de Rotterdamse haven voor georganiseerde misdaad, omdat hun medewerkers door criminelen worden gebruikt om het plegen van die misdaad te faciliteren. Het zou worden uitgevoerd door middel van een analyse van de relevante incidenten in de voorbije twintig jaar: opzettelijke schendingen van de integriteit 
door personeelsleden, waarbij sprake is van vrijwillige of onvrijwillige samenwerking met criminelen.

Het uitgangspunt was: wat gebeurt er als je in de haven de controle opvoert? Neemt dan - paradoxaal genoeg - de kwetsbaarheid van de THOR-organisaties voor corruptie niet toe omdat zij er vermoedelijk beter in zullen slagen illegale activiteiten te belemmeren? De relevantie van deze vraagstelling was niet alleen gebaseerd op de hiervoor besproken onderzoeken naar de drugssmokkel in de Rotterdamse haven, maar was ook gelegen in het feit dat in 2016 forse aanscherping van de controle aan de orde was, met name in het kader van het project Integere/Veilige Haven. Hiertoe kan worden verwezen naar de brief van de Staatssecretaris van Financiën d.d. 2 november 2016 over de versterking van de rol van de douane - in termen van meer samenwerking met andere (publieke en private) partijen - bij de bestrijding van ondermijnende criminaliteit in de haven, in het bijzonder de drugssmokkel. ${ }^{5}$

In de voorbije drie jaar werd allerlei onderzoek gedaan. Samengevat werden negentien dossiers van strafzaken in de voorbije twintig jaar achterhaald, werd er in totaal met 119 personen gesproken en werden tal van signalen inzake (mogelijke) incidenten verzameld die niet tot een opsporingsonderzoek/strafzaak hadden geleid. En in het voorjaar van 2019 lag er het concept van het eindrapport. Dit concept werd echter niet uitgewerkt tot een publicatie. Waarom niet? Omdat, zoals de onderzoekers in de Toelichting d.d. 12 mei 2019 bij deze beslissing schreven, zij er onvoldoende in waren geslaagd om vast te stellen wat de bedoelde signalen in empirische zin zeggen over de aard en omvang van integriteitsschendingen in de rangen van de genoemde organisaties: 'We kunnen geen onomstotelijke en geldige uitspraken doen over het aantal en soort incidenten dat heeft plaatsgevonden.' En waarom niet? Om diverse redenen, maar veruit de belangrijkste reden was de onvoldoende beschikbaarheid van schriftelijke bronnen/registraties. En de voornaamste reden hiervan was weer dat een aantal THOR-organisaties in de haven formeel of feitelijk geen medewerking wilde verlenen aan het onderzoek. Met het wat bizarre gevolg dat terwijl de onderzoekers steeds meer signalen ter ore kwamen, de THORorganisaties steeds meer de luiken dichtdeden. Deze ervaring was reden om aan het slot van de Toelichting te stellen dat alleen een par- 
lementaire of statelijke onderzoekscommissie voldoende is gewapend om door te dringen tot de integriteitsproblemen die in werkelijkheid spelen bij de THOR-organisaties in de Rotterdamse haven.

Het ligt voor de hand dat deze ongebruikelijke gang van zaken in politieke en wetenschappelijke kringen vragen oproept. In antwoord op vragen van Kamerleden schrijft de Minister van Justitie en Veiligheid op 19 juli 2019 aan de Tweede Kamer dat hij niet wil treden in de overwegingen van de onderzoekers om geen eindrapport uit te brengen. ${ }^{6}$ Hij voegt er echter geruststellend aan toe dat er voldoende andere recente onderzoeken zijn om het beleid rondom integriteit en de bestrijding van ondermijnende criminaliteit en corruptie nader vorm te geven. De onderzoeken waar hij naar verwijst (Nelen \& Kolthoff 2017; Smit e.a. 2019; Staring e.a. 2019), zijn echter niet specifiek gericht op het probleem van non-integriteit respectievelijk corruptie bij overheidsdiensten in de Rotterdamse haven, en zeker niet op signalen waarvan de integriteitsbureaus van de Nationale Politie en de Koninklijke Marechaussee, de Rijksrecherche, de FIOD of het Openbaar Ministerie geen weet hebben. Hierom is het niet te veel gezegd dat de minister in zijn brief van 19 juli 2019 met een forse boog om het probleem heen loopt. Dat er zo'n probleem bestaat, staat echter buiten kijf. Dat blijkt niet alleen uit goed gedocumenteerde gevallen als dat van de voormalige douanier $\mathrm{G}$ (Meeus 2019). Het kan ook worden opgemaakt uit de brief van de Staatssecretaris van Financiën d.d. 22 augustus 2019 over de versterking van de screening bij de douane door haar op het niveau van de politie te brengen. ${ }^{7}$

\section{Een korte blik in de toekomst}

Men moet er - met het World Drug Report 2019 van het UN Drugs and Crime Office - voorlopig van blijven uitgaan dat de productie en het gebruik van cocaïne, en hiermee de druk op de Nederlandse en Belgische havens, niet zullen afnemen. En hier komt de invoer van andere illegale drugs nog bij: methamfetamine uit Mexico, heroïne uit Iran en cannabis uit Nigeria, zoals uit recente krantenberichten blijkt. Het is dan ook raadzaam om niet weg te kijken van het probleem van de non-integriteit in de Rotterdamse haven. Integendeel: de analyse van

6 Kenmerk van de brief: 2632129.

7 Kenmerk van de brief: 2019-0000116093. 
Staring en collega's betreffende de structurele kwetsbaarheden van/in de Rotterdamse haven moet daadkrachtig worden doorgetrokken tot op het niveau van de mensen die hier in publiek dan wel particulier verband werkzaam zijn. Alleen op dit niveau kan nauwkeurig genoeg worden achterhaald hoe die structurele kwetsbaarheden verder kunnen worden verminderd. En als de betrokken overheden en diensten niet bij machte zijn om deze oefening grondig genoeg te maken, is er inderdaad alle reden om een parlementaire of statelijke commissie dit te laten uitzoeken. Alleen zo kan worden tegengegaan dat persoonlijke non-integriteit een structureel probleem in de haven wordt. Met het risico dat criminele groepen hier feitelijke machtsposities in de afhandeling van goederen(stromen) opbouwen die zeer moeilijk af te breken zijn. Het feit dat Nederland geen maffia, cosa nostra of yakuza kent, wil niet zeggen dat zo'n ontwikkeling hier onmogelijk is.

\section{Literatuur}

\section{Arlacchi 1986}

P. Arlacchi, Mafia business. The mafia ethic \& the spirit of capitalism, Londen: Verso 1986.

\section{Berkelder \& De Ree 2015}

N. Berkelder \& H. de Ree, 'WildWest op de Noordzee', BN-De Stem 3 juni 2015.

\section{Boerman e.a. 2017}

F. Boerman, M. Grapendaal, F. Nieuwenhuis \& E. Stoffers, Nationaal dreigingsbeeld 2017 georganiseerde criminaliteit, Zoetermeer: Dienst Landelijke Informatieorganisatie 2017.

\section{Carroll 1991}

B. Carroll, 'Combatting racketeering in the Fulton Fish Market', in: C. Fijnaut \& J. Jacobs (red.), Organized crime and its containment. A transatlantic initiative, Deventer: Kluwer 1991, p. 183-200.

\section{Colman e.a. 2018}

C. Colman, F. De Middeleer,

A. Spapens, S. Van Nimwegen e.a., De grens voorbij. Belgische en Nederlandse drugsmarkten in beweging, Den Haag: Boom criminologie 2018. 


\section{Commissione parlamentare 2008}

Commissione parlamentare di inchiesta sul fenomeno della criminalità organizzata mafiosa o similare, Relazione annuale sulla 'ndrangheta (Doc. XXIII, N. 5), 19 februari 2008.

\section{Eski \& Buijt 2016}

Y. Eski \& R. Buijt, 'Dockers in drugs. Policing the illegal drug trade and port employee corruption in the Port of Rotterdam', Policing: A Journal of Police and Practice (11) 2016, afl. 4, p. 371-386.

\section{Fijnaut 1985}

C. Fijnaut, 'Georganiseerde misdaad. Een onderzoeksgerichte terreinverkenning', Justitiële verkenningen 1985, afl. 9, p. 5-42.

\section{Fijnaut 1989}

C. Fijnaut (red.), Georganiseerde misdaad en strafrechtelijk politiebeleid, Lochem: J.B. van den Brink 1989.

\section{Jacobs e.a. 1999}

J. Jacobs, C. Friel \& R. Radick, Gotham unbound. How New York City was liberated from the grip of organized crime, New York: New York University Press 1999.

\section{Kleemans e.a. 2002}

E. Kleemans, M. Brienen \& H. van de Bunt, Georganiseerde criminaliteit in Nederland, Den Haag: WODC 2002.

\section{Madarie \& Kruisbergen 2018}

R. Madarie \& E. Kruisbergen, Traffickers in transit. Analysing the logistics and involvement mechanisms of organised crime at logistical nodes in the

Netherlands. Empirical results of the Dutch Organised Crime Monitor, 2018.

\section{Marx 1984}

G. Marx, 'Notes on the discovery, collection and assessment of hidden and dirty data', in: J. Schneider \& J. Kitsuse (red.), Studies in the sociology of social problems, Norwood, NJ: Ablex Publishing Corporation 1984, p. 78-113.

\section{Meeus 2019}

J. Meeus, De Schiedamse cocaïne maffia. Een corrupte douanier, doorgewinterde criminelen en duizenden kilo's coke, Amsterdam: Nieuw Amsterdam 2019.

\section{Nelen \& Kolthoff 2017}

H. Nelen \& E. Kolthoff, Schaduwen over de rechtshandhaving. Georganiseerde criminaliteit en integriteitsschendingen van functionarissen in de rechtshandhaving. Den Haag: Boom criminologie 2017.

\section{Paoli 2003}

L. Paoli, Mafia brotherhoods. Organized crime, Italian style, New York: Oxford University Press 2003. 


\section{Politie 2008}

Politie, Cocaïnehandel, Driebergen: Dienst Nationale Recherche 2008.

\section{Smit e.a. 2019}

A. Smit, N. Slagmolen, C. Bronkhorst, J. van den Goor \&

G. Meershoek, Het lekken van vertrouwelijke politie-informatie. Aard, omvang en ernst van het fenomeen bij de Nationale Politie en de Koninklijke Marechaussee, Den Haag: Boom criminologie 2019.

\section{Staring e.a. 2019}

R. Staring, L. Bisschop, R. Roks, E. Brein e.a., Drugscriminaliteit in de Rotterdamse haven. Aard en aanpak van het fenomeen, Den Haag: Boom criminologie 2019.

\section{White 2018}

B. White, Mafia and globalization. The consequences of economic integration without legal symmetry, San Diego: University of San Diego 2018.

\section{Zaitch 2001}

D. Zaitch, Traquetos. Colombians involved in the cocaine business in the Netherlands, Amsterdam: Universiteit van Amsterdam 2001.

\section{Zaitch 2002}

D. Zaitch, 'From Cali to Rotterdam. Perceptions of Colombian cocaine traffickers on the Dutch Port', Crime, Law \& Social Change (38) 2002, afl. 3, p. 239-266. 